\title{
A LINGUAGEM \\ DE UMA FRAUDE: \\ ANÁLISE DAS \\ FALSAS CONFISSÕES \\ ATRIBUÍDAS \\ AOS IRMÃOS \\ NAVES
}

\section{EL LENGUAJE DE UN FRAUDE: ANÁLISIS DE LAS FALSAS CONFESIONES ATRIBUIDAS A LOS HERMANOS NAVES}

THE LANGUAGE OF A FRAUD: ANALYSIS OF THE FALSE CONFESSIONS ATTRIBUTED TO THE NAVES BROTHERS

Evandro L. T. P. Cunha*

Universidade Federal de Minas Gerais

César Nardelli Cambraia**

Universidade Federal de Minas Gerais

RESUMO: No caso dos irmãos Naves, ocorrido no Brasil na primeira metade do século XX, alegou-se que eles teriam confessado o cometimento de um crime que sequer aconteceu. Neste artigo, é apresentada uma análise linguística e discursiva das confissões forjadas que foram atribuídas a eles, baseando-se, do ponto de vista teórico-metodológico, em estudos prévios acerca de características comuns a falsas narrativas no âmbito da linguística forense e na aplicação de método inspirado na crítica textual. Foi possível identificar elementos linguísticos que denunciam a falsidade das confissões atribuídas aos irmãos, como uma descrição

\footnotetext{
* Doutor em Linguística pela Universiteit Leiden e em Ciência da Computaça pela Universidade Federal de Minas Gerais, em regime de cotutela; especialista em Linguística Forense pela Universidade do Porto; professor de Língua Italiana e Linguística Aplicada na Faculdade de Letras da Universidade Federal de Minas Gerais. E-mail: cunhae@ufmg.br.

* Doutor em Filologia e Língua Portuguesa pela Universidade de São Paulo; professor titular de Filologia Românica (Linguística Românica e Crítica Textual) na Faculdade de Letras da Universidade Federal de Minas Gerais; Bolsista de Produtividadeem PesquisadoCNPq. E-mail: nardelli@ufmg.br.
} 
extremamente minuciosa do suposto crime, a presença de erros, inconsistências e contradições no discurso e a utilização de linguagem de incerteza. Além disso, a comparação entre as duas confissões permitiu verificar a presença de eco e de padrões de condensação e expansão. Embora limitado pela natureza dos dados, este estudo fornece subsídios para discussões sobre como melhor caracterizar falsas confissões em contextos investigativos e judiciais.

PALAVRAS-CHAVE: Linguística forense. Crítica textual. Falsas confissões. Erros judiciais. Caso dos irmãos Naves.

RESUMEN: En el caso de los hermanos Naves, sucedido en Brasil en la primera mitad del siglo XX, se alegó que ellos habían confesado la comisión de un crimen que ni siquiera ocurrió. En este artículo, se presenta un análisis lingüístico y discursivo de las confesiones forjadas que se les atribuyen a ellos, basándose, desde el punto de vista teórico-metodológico, en estudios anteriores sobre las características comunes de falsas narrativas en el campo de la lingüística forense y en la aplicación de método inspirado en la crítica textual. Fue posible identificar elementos lingüísticos que denuncian la falsedad de las confesiones atribuidas a los hermanos, como una descripción extremadamente detallada del presunto crimen, la presencia de errores, inconsistencias y contradicciones en el discurso y el uso de lenguaje de incertidumbre. Además, la comparación entre las dos confesiones permitió verificar la presencia de eco y patrones de condensación y expansión. Aunque estélimitado por la naturaleza de los datos, este estudio brinda apoyo para las discusiones sobre cómo caracterizar mejor falsas confesiones en contextos investigativos y judiciales.

PALABRAS CLAVE: Lingüística forense. Crítica textual. Falsas confesiones. Errores judiciales. Caso de los hermanos Naves.

ABSTRACT: In the case of the Naves brothers, occurred in Brazil in the first half of the 20th century, it was alleged that they confessed to committing a crime that did not even happened. In this article, we present a linguistic and discursive analysis of the confessions forged and attributed to them, based, from a theoretical-methodological point of view, on previous studies on common characteristics of false narratives in the field of forensic linguistics and on the application of a method inspired by textual criticism. We identified linguistic elements that indicate the falsity of the confessions attributed to the brothers, such as the extremely detailed description of the alleged crime, the presence of mistakes, inconsistencies and contradictions in the discourse and the use of language of uncertainty. We also compared these confessions and verified the presence of echo and patterns of condensation and expansion. Although limited by the nature of the data, this study enriches discussions on how to characterize false confessions in investigative and judicial contexts.

KEYWORDS: Forensic linguistics. Textual criticism. False confessions. Miscarriages of justice. Case of the Naves brothers.

\section{INTRODUÇÃO}

Em âmbito criminal, uma falsa confissão pode ser definida como a confissão do cometimento de um crime por parte de um ou mais indivíduos inocentes ou, ainda, uma confissão deliberadamente forjada para incriminar alguém. Trata-se de uma grave situação em contextos investigativos e judiciais, já que uma confissão é geralmente considerada um importante meio de prova - porém não absoluto, pois, nos sistemas jurídicos modernos, “[...] para ser aceita como fundamento de culpabilidade, tem de ser confrontada com as demais provas produzidas" (DUTRA, 2015, p. 188). Isso diz respeito ao que, na visão tradicional dos estudos jurídicos, se chama de princípio da verdade real no âmbito do direito penal: "[a] narração do fato, que, nas denúncias e nas queixas, o denunciante ou querelante deve empreender, não vincula o magistrado às circunstâncias narradas, senão na medida em que estas se ajustam às do fato real objetivo." (ALMEIDA, 1957, p. 116). Uma falsa confissão pode, portanto, interferir nos rumos de uma investigação, ajudando a culpar indivíduos inocentes e a absolver indivíduos culpados.

Falsas confissões apresentam-se como enigmas para o sistema judiciário, pois o que poderia levar uma pessoa a reconhecer o cometimento de um crime sobre o qual não possui responsabilidade? De acordo com Gudjonsson e Sigurdsson (1994) e Garrett (2010), os principais motivos alegados para a realização de uma falsa confissão são o interesse em proteger outra pessoa, o desejo de pôr fim à tortura física e psicológica praticada pelas autoridades policiais e o medo de sofrer uma punição mais severa (por exemplo, pena de morte) em caso de condenação sem confissão. Gudjonsson e Sigurdsson (1994) acrescentam que, em seu estudo envolvendo 229 prisioneiros, $12 \%$ afirmaram já terem proferido falsa confissão durante um interrogatório policial, o que demonstra ser esse um problema relevante no contexto das ciências forenses.

Cunha \& Cambraia A linguagem de uma fraude: análise das falsas confissóes atribuídas aos irmãos Naves 
Vários outros trabalhos com as mais diferentes abordagens já trataram do assunto das falsas confissões. Neiva (2008) estudou confissões e falsas confissões a partir da perspectiva de investigadores mais e menos experientes. A autora cita Kassin e Wrightsman (1985) ao mencionar a tradicional categorização de uma falsa confissão como voluntária (que ocorre sem pressão externa), coagida por obediência (em que o acusado confessa a realização do crime para escapar de uma situação indesejada, como tortura) ou coagidainternalizada (quando o confessor cria falsas memórias e passa realmente a acreditar que cometeu o crime). Drizin e Leo (2004) e Garrett (2015), ao analisarem corpora de falsas confissões, mostram que, em geral, um depoimento desse tipo é particularmente crível e verossímil, o que dificulta sua identificação como falso. Uma série de traços relacionados a características pessoais de um suspeito - por exemplo, à sua idade e à sua condição mental - já foi identificada como fator de risco para a ocorrência de falsas confissões (GREBLER, 2010). Entretanto, é necessário avançar na abordagem linguística do problema, buscando responder à seguinte questão: quais são as características linguísticas presentes em uma confissão que podem permitir suspeitar que aquela não seja uma confissão genuína?

O principal objetivo deste artigo é contribuir para a análise das características linguísticas presentes em falsas confissões a partir de um estudo de caso: realiza-se aqui uma investigação sobre falsas confissões pertencentes ao caso dos irmãos Naves, um emblemático caso de erro judicial ocorrido no Brasil, na primeira metade do século XX. Assim, preenche-se ainda uma outra lacuna, que é a raridade de análises a respeito dessa questão em casos brasileiros. Do ponto de vista teórico-metodológico, este estudo se baseia em conceitos oriundos de investigações sobre falsas narrativas (GARRETT, 2010, 2015; GREBLER, 2010) e em métodos da crítica textual (CAMBRAIA, 2005), pois as falsas confissões atribuídas aos irmãos Naves são analisadas a partir de: (a) conhecimentos obtidos em estudos anteriores que examinaram o conteúdo de falsas narrativas e identificaram características linguísticas e discursivas comuns a esses textos; e (b) métodos de comparação entre textos inspirados na crítica textual.

Na próxima seção, o caso dos irmãos Naves é brevemente apresentado a fim de oferecer o contexto necessário para a compreensão das observações. Em seguida, são apresentadas a metodologia utilizada para a realização da pesquisa e as análises executadas sobre as confissões forjadas em nome dos irmãos Naves. Finalmente, os resultados encontrados são discutidos e conclui-se o artigo mencionando as contribuições deste trabalho e as possíveis abordagens que poderão ser consideradas em trabalhos futuros. Este texto conta ainda com a seção Anexo A, em que são disponibilizadas as declarações dos irmãos Naves aqui consideradas.

\section{O CASO DOS IRMÃOS NAVES}

Caso dos irmãos Naves é o nome dado aos acontecimentos referentes à prisão dos irmãos Joaquim e Sebastião Naves, injustamente acusados de um crime que teria ocorrido em 1937 no interior do estado de Minas Gerais. É um dos mais famosos erros judiciais da história do Brasil e obteve grande repercussão, tendo sido inclusive relatado pelo filme O caso dos irmãos Naves, de 1967.

\subsection{BREVE RESUMO DOS ACONTECIMENTOS}

Os irmãos Joaquim Rosa Naves, de 25 anos, e Sebastião José Naves, de 32 anos, eram trabalhadores rurais e pequenos comerciantes na região de Araguari, Minas Gerais. Benedito Pereira Caetano, primo deles e sócio de Joaquim, desapareceu sem deixar rastros, mas com uma razoável quantia em dinheiro decorrente de uma negociação. Preocupados com o sumiço de Benedito, os irmãos Naves informaram o ocorrido à polícia. As investigações se iniciaram e, após alguns dias, os próprios Joaquim e Sebastião foram tidos como suspeitos pelas autoridades policiais, foram presos e passaram a sofrer tortura para que confessassem um suposto roubo seguido do assassinato de Benedito. De acordo com o Museu do Judiciário Mineiro (2017),

[a]pós intensas torturas dos irmãos, o delegado detém a mãe dos acusados, Ana Rosa Naves, que é espancada e seviciada, bem como as esposas e filhos dos acusados. Diante de tanto sofrimento, em 12 de janeiro de 1938, Joaquim termina por assinar a confissão do latrocínio [...] (crime no qual, durante o ato de roubar ou em decorrência dele, ocorre a morte da vítima). Criada a história, faltava a materialidade e prosseguem as atrocidades e os constantes desrespeitos à lei. 
Algumas semanas depois, Sebastião também confessou o suposto crime. Apesar das confissões, nenhuma prova material foi encontrada - nem mesmo o dinheiro ou o corpo de Benedito:

[o] delegado levou Joaquim para que pudesse reconstituir o crime. Também houve busca e apreensão, que resultou negativa, já que não foram encontrados o pano que envolvia o dinheiro e muito menos a lata com os noventa contos. Não havia o que procurar, era impossível encontrar objetos que nunca foram usados, pois tal crime não havia ocorrido. Também não se achava o cadáver de Benedito. Destarte, ignora-se o exame do corpo de delito direto ou indireto, e baseia-se somente em uma "confissão". (SILVA, 2010, p. 81)

Diante da ausência de provas materiais, os irmãos Naves foram absolvidos em dois julgamentos. No entanto,

[a] Constituição de 1937, embora tenha mantido o Tribunal do Júri [...] retirou-lhe a soberania, podendo os tribunais superiores reformar suas sentenças. Assim, atendendo à apelação do Ministério Público e sob forte pressão da mídia, em 04 de Julho de 1939, o Tribunal de Justiça, ignorando a fragilidade das provas contra os réus, caça a decisão absolvitória e decreta o fim das apelações. Os réus são condenados à pena de 25 anos e 6 meses de prisão pelo crime de latrocínio. (MUSEU DO JUDICIÁRIO MINEIRO, 2017)

Em 1946, os irmãos Naves conseguem a liberdade condicional. Dois anos depois, morre Joaquim, sem conhecer a reviravolta que o caso sofreria em 1952, quando

Benedito Pereira Caetano reaparece vivo na fazenda de seus pais, em Nova Ponte. Ele é visto por [José] Prontidão, que avisa sobre a "ressurreição de Benedito" a Sebastião, o qual acompanhado de alguns policiais e de um repórter do Diário de Minas, dirigem-se à fazenda para reencontrar o primo, tido como morto por todos aqueles anos. (SILVA, 2010, p. 83)

O erro jurídico é então reconhecido pelo Estado, o processo é anulado e, em 1960, 23 anos depois da ocorrência dos erros iniciais, os irmãos Naves recebem direito a indenização pelos danos morais e materiais sofridos.

\subsection{TRABALHOS RELACIONADOS AO CASO DOS IRMÃOS NAVES}

O célebre erro judiciário envolvendo Joaquim e Sebastião Neves é mencionado em diversas publicações de interesse geral. Entre elas, destaca-se o livro do jurista Dotti (2003), que apresenta notórios casos criminais analisados sob a ótica do direito penal atual. O artigo de Silva (2010) apresenta o caso em questão e relaciona os fatos narrados aos eventos apresentados pelo filme O caso dos irmãos Naves, de 1967.

O poder da coerção e do aparato policial no caso dos irmãos Naves é analisado por Sousa (1996), que argumenta que a condenação dos irmãos se deu a partir da "[...] intimidação das testemunhas e informantes conseguida após sessões de torturas, espancamentos e seviciamentos" (p. 6) e considera esse fato um reflexo do período ditatorial em que vivia o Brasil naquele momento.

Figueiredo (2015) realiza uma ampla investigação do caso a partir de uma visão jurídica e, em especial, da criminologia crítica, com análise dos indícios e dos erros judiciais cometidos nessa ocasião. Biz (2012) também estuda os erros judiciais no processo de Joaquim e Sebastião e, ainda sob uma abordagem jurídica, Silva (2011) analisa o princípio da presunção de inocência baseado nesse célebre caso, dando ênfase à relação entre a não-culpabilidade e a pressão da mídia e mencionando que, no caso de Joaquim e Sebastião, o veredito do júri foi alterado para satisfazer à opinião pública.

Uma diferente e interessante abordagem é tomada por Oliveira (2012, 2013), que analisa de que forma o caso dos irmãos Naves serviu como inspiração para trabalhos artísticos sobretudo nas áreas da literatura, do cinema, da música e da televisão, "[...] demonstrando o valor das artes para a perpetuidade e ressignificação da memória social” (OLIVEIRA, 2013, p. 8). 
Entretanto, a fonte de informações mais interessante sobre o caso dos irmãos Naves é certamente o livro do advogado dos réus, João Alamy Filho, que teve sua primeira edição publicada em 1961 (ALAMY FILHO, [197-?]). Nesse livro, analisado como obra literária por Rodrigues (2011), Alamy Filho conta detalhes do inquérito policial, da instrução criminal, dos julgamentos e, finalmente, da anulação do processo envolvendo Joaquim e Sebastião Naves. Cópias e transcrições de vários documentos acompanham os relatos do advogado, tornando assim possível a análise de diversos elementos referentes a esse caso por meio de documentação disponibilizada.

\section{METODOLOGIA}

Neste estudo, as falsas confissões atribuídas a Joaquim e Sebastião Naves são analisadas com base nas observações presentes em trabalhos anteriores sobre o tema no âmbito da linguística forense e em método inspirado na crítica textual. Para isso, procedeu-se inicialmente à obtenção e à leitura das confissões atribuídas aos irmãos a partir dos autos do processo criminal em questão, cuja cópia está disponível em formato PDF no endereço Web do Museu do Judiciário Mineiro (2017), autos estes que totalizam 760 páginas distribuídas em três volumes. A confissão atribuída a Joaquim Naves consta das folhas $25 \mathrm{r}$ a $27 \mathrm{r}$ e a de Sebastião Naves das folhas $98 \mathrm{r}$ a 99v do primeiro volume (na numeração aplicada pelo Cartório Criminal Jair Passos, de Araguari). As transcrições dessas confissões estão disponíveis como anexos deste artigo: embora as referidas transcrições tenham sido publicadas anteriormente por Alamy Filho ([197-?], p. 61-63 e 127-129), considerou-se aqui necessário realizar uma nova transcrição, para corrigir lapsos e respeitar as características da linguagem da época e do próprio processo de seu registro. Apesar de estarem presentes nos autos do processo diversas outras falsas declarações - não apenas dos irmãos Naves, mas também de seus familiares, que foram coagidos a reconhecer a autoria do crime pelos irmãos -, este estudo se detém apenas na análise das duas confissões iniciais atribuídas aos irmãos Naves, desconsiderando assim os adendos e as correções que surgem em declarações posteriores.

É importante observar que não se sabe exatamente como aconteceram as declarações confessionais dos irmãos Naves: teriam eles, sob coação, apresentado oralmente um falso relato ou apenas assinado documentos contendo narrativa previamente forjada e lavrada? Além disso, deve-se destacar que, caso tenham acontecido relatos orais, as declarações terão provavelmente sido mediadas pela autoridade policial na forma de ditados registrados por um escrivão - ou seja, o escrivão registrou o que foi ditado pelo investigador e não o que os acusados supostamente falaram. Há, portanto, um processo de retextualização que impede que se tenha acesso direto à voz dos acusados e transforma as declarações em registros da voz da autoridade. Esses fatos dificultam e, por vezes, até impossibilitam a realização de certas análises sobre o conteúdo das falsas confissões atribuídas a Joaquim e Sebastião Naves.

A partir da revisão de literatura, foram selecionadas as três seguintes características linguísticas e discursivas ${ }^{1}$ observadas em falsas confissões:

1. Descrição extremamente minuciosa do suposto crime: Garrett (2010) menciona que, em 97\% dos casos analisados em seu corpus, os inocentes não apenas confessaram crimes que não cometeram, mas também deram informações surpreendentemente ricas e detalhadas sobre eles.

2. Presença de erros, inconsistências e contradições no discurso: Garrett (2010) também indica que, frequentemente, falsas confissões contêm informações que se mostram inconsistentes com outras evidências, como depoimentos de outros suspeitos e testemunhas.

3. Utilização de linguagem de incerteza: Grebler (2010) sugere que a linguagem utilizada em falsas confissões se caracteriza pela presença de elementos linguísticos e discursivos que indicam dúvida, hesitação e indecisão.

Em ambas as declarações, analisaram-se a presença e a ausência de cada uma das características apontadas acima, visando identificar até que ponto esses elementos podem ser identificados também nas falsas confissões atribuídas aos irmãos Naves.

\footnotetext{
${ }^{1}$ As características linguísticas dizem respeito à escolha de estruturas linguísticas específicas e as características discursivas referem-se à escolha de tópicos/conteúdos específicos.
} 
Além disso, considerando que as confissões em questão são indubitavelmente falsas, o corpus desta análise abre espaço para que se busquem padrões linguísticos e textuais não contemplados em estudos anteriores sobre falsas confissões, mas que se mostraram salientes em sua análise: tem-se assim a oportunidade de contribuir para a identificação de novos aspectos relevantes. Por se tratar de um caso de confissão dupla, é possível identificar elementos de interesse a partir da comparação entre as declarações dos dois acusados. Para isso, incorporou-se neste estudo uma técnica do campo da crítica textual chamada de colação - procedimento utilizado para se compararem diferentes versões de um texto a fim de se localizarem os pontos em que os textos divergem ou se assemelham (CAMBRAIA, 2005, p. 135-136). A pertinência dessa técnica para o caso em questão reside no fato de que se trata de uma situação especial, com duas falsas confissões referindo-se a um mesmo suposto crime: a técnica da colação, em função de sua comparação minuciosa, passagem a passagem do texto, permite identificar com mais precisão pontos sutis de convergência e divergência entre essas confissões. Foi essa comparação minuciosa que permitiu observar a presença de características a que se nomeou aqui de eco e de padrões de condensação e expansão. A pertinência da crítica textual para a detecção de fraudes tem sido reconhecida em uma perspectiva interdisciplinar:

[a] linguística já desenvolveu uma série de disciplinas que podem apoiar a investigação destas fraudes. Trata-se agora de articular os axiomas de cada uma delas e de problematizar a forma como eles se complementam no contexto deste desafio. As disciplinas em causa são sobretudo a análise do discurso, a pragmática, a sintaxe, a crítica textual, a linguística histórica, a sociolinguística e a linguística de corpus. (MARQUILHAS; CARDOSO, 2012, p. 418)

Na próxima seção, são apresentadas e discutidas as análises e as observações mencionadas acima.

\section{ANÁLISE E DISCUSSÕES}

\subsection{ANÁLISE DE CARACTERÍSTICAS LINGUÍSTICAS E DISCURSIVAS PREVIAMENTE OBSERVADAS EM FALSAS CONFISSÕES}

Nesta seção, as falsas confissões atribuídas a Joaquim e Sebastião Naves são analisadas com referência a três características linguísticas e discursivas comuns a falsas confissões, de acordo com a literatura consultada: (a) descrição extremamente minuciosa do suposto crime; (b) presença de erros, inconsistências e contradições no discurso; e (c) utilização de linguagem de incerteza.

\subsubsection{Descrição extremamente minuciosa do suposto crime}

De acordo com Garrett (2010), a grande maioria das falsas confissões contêm informações surpreendentemente ricas e detalhadas acerca do crime. Isso provavelmente se deve ao fato de que, em uma narrativa inventada, não há razões para esquecimento de detalhes - afinal, qualquer detalhe pode ser inventado a qualquer momento, desde que esteja condizente com as demais informações previamente concedidas. Esse detalhismo funciona como um elemento que confere um efeito de real à narrativa (BARTHES, 1972, p. 43): essa característica tem como função fazer o ouvinte/leitor acreditar que o fato narrado efetivamente existiu.

As confissões tanto de Joaquim quanto de Sebastião Naves possuem essa característica. Além de descreverem o suposto plano dos irmãos, elas abordam em detalhes como teriam acontecido o roubo do dinheiro e a execução de Benedito.

O sumiço de Benedito se deu em 29 de novembro de 1937. A falsa confissão de Joaquim teria ocorrido um mês e meio depois (em 12 de janeiro de 1938), enquanto a de Sebastião teria ocorrido mais de dois meses depois (em 3 de fevereiro de 1938). Seria natural que determinados detalhes, como o horário em que ocorreram os eventos, tivessem sido esquecidos pelos acusados. Entretanto, $\mathrm{o}$ nível de detalhe com que as informações aparecem nas declarações impressiona. E, mais do que isso, chama a atenção o fato de que os mesmos detalhes estejam presentes nas duas falsas confissões em formato muito parecido. Um exemplo é o horário em que 
Joaquim, Sebastião e Benedito teriam saído para um passeio: as duas declarações trazem essa informação - "ás treis horas da (mesma) madrugada":

[...] entrando no mesmo momento todos os treis para dentro do caminhão pondo-o em marcha, tomando a direção da ponte "Pau Furado", isto ás treis horas da madrugada. (Declaração de Joaquim, f. 25 v, grifo nosso)

[...] partindo todos os treis no caminhão de Joaquim, ás treis horas da mesma madrugada. (Declaração de Sebastião, f. 98v, grifo nosso)

Há que se salientar que essa preocupação com horário dos eventos tem sua razão em termos de persecução penal: um álibi só terá relevância se for compatível com o momento em que se alega ter sido cometido um crime. No caso em questão, o horário teria como objetivo justamente o inverso: impossibilitar qualquer álibi.

Chama também a atenção o fato de haver descrição detalhada do recipiente em que o dinheiro teria sido colocado pelos irmãos Naves. Não se informa apenas que se trata de uma lata, como ainda há o detalhe de ser uma lata de soda:

[...] o seu irmão Sebastião, depositou em uma latinha de soda adrede preparada pelo o $($ sic $)$ declarante para esse mesmo fim que transportou-a de sua casa. (Declaração de Joaquim, f. 26r, grifo nosso)

[...] depois de retirar o dinheiro da cintura de Benedito o declarante colocou o dito dinheiro em uma lata de soda. (Declaração de Sebastião, f. 98v, grifo nosso)

Também interessante é a minuciosidade na descrição do posicionamento espacial dos envolvidos nos eventos:

[...] desceram o paredão até a margem do rio, estando o seu irmão na frente, Benedito no centro e o declarante atrás. (Declaração de Joaquim, f. 25v, grifo nosso)

\subsubsection{Presença de erros, inconsistências e contradições no discurso}

Garrett (2010) mostra ainda que uma das características comuns a falsas narrativas, em geral, é a presença de contradições. No âmbito investigativo, as contradições no discurso surgem frequentemente como um elemento incriminador do acusado, sugerindo, por exemplo, a inveracidade de um álibi. No entanto, as contradições podem ser indícios de qualquer falsidade narrativa, o que significa que podem ser esperadas também no contexto das falsas confissões.

Inconsistências no discurso podem ser reflexos do já mencionado excesso de minúcias na descrição, pois, devido ao grande número de detalhes, o depoente pode acabar confundindo-se com alguns. No caso dos irmãos Naves, Alamy Filho ([197-?]) elenca ao menos duas contradições entre as falsas confissões atribuídas a Joaquim e a Sebastião:

Sebastião [...] declara que ao pegar Benedito pelas costas, [...] Joaquim já tinha levado a corda com que enforcaram Benedito, com o nó feito; Joaquim [...] declara que, quando Sebastião prendeu Benedito pelas costas, apanhou uma corda e lhe deu um nó, com que enforcaram a vítima. (Alamy Filho, [197?], p. 131) 
Sebastião [...] diz que mandou Joaquim buscar o dinheiro no esconderijo, à beira do rio [...]; Joaquim [...] diz que Sebastião foi lá e retirou o dinheiro. (Alamy Filho, [197-?], p. 131)²

Pode-se argumentar que a primeira dessas contradições é apenas um detalhe que pode ter sido esquecido por um dos acusados. Entretanto, a segunda inconsistência não é um mero detalhe: é pouco provável que alguém se esqueça de que se tenha dirigido a um esconderijo, próximo do local de um assassinato, a fim de buscar uma grande quantia de dinheiro.

Outra contradição está nas informações apresentadas em relação ao conhecimento do valor de cuja posse estaria Benedito. Joaquim diz que ambos os irmãos já sabiam do valor, mas Sebastião diz que o valor só foi conhecido depois de fazer busca no cadáver:

[...] onde o declarante e o seu irmão sabia $(s i c)$ que existia a importancia mais ou menos de noventa contos de reis em dinheiro. (Declaração de Joaquim, f. 26r, grifo nosso).

[...] no qual o declarante verificou mais tarde conter a importancia de noventa contos de reis, embora o seu irmão Joaquim dizer que o mesmo continha noventa e dois contos de reis, podendo o declarante estar enganado neste ponto. (Declaração de Sebastião, f. 98v, grifo nosso)

Na própria declaração de Sebastião, emerge ainda a questão da contradição no que se refere ao valor: Sebastião diz que Joaquim alegara serem 92 contos de réis, embora na declaração de Joaquim conste serem 90 contos. A questão da contradição na temporalidade do conhecimento do valor (antes de fazer busca no cadáver x depois de fazer busca no cadáver) passa em branco.

\subsubsection{Utilização de linguagem de incerteza}

Segundo Grebler (2010), a linguagem de incerteza (language of uncertainty) se caracteriza pela utilização de elementos linguísticos que indicam dúvida, hesitação e indecisão. Entre esses elementos, podem ser destacados a falta de clareza na narrativa, a presença excessiva de pausas e de autocorreção, além de formas verbais nos modos subjuntivo e condicional.

Não foi possível avaliar com segurança até que ponto as falsas confissões atribuídas aos irmãos Naves possuem essa característica, já que não estão disponíveis as transcrições das falas dos acusados, mas apenas o ditado por parte da autoridade policial. Esse é um dos motivos pelos quais se recomenda que declarações e depoimentos sejam fielmente transcritos, gravados ou até filmados, conforme sugere Broholm (2011).

Entretanto, é possível perceber diferentes ocasiões de insegurança em relação à informação prestada, sobretudo com referência a horários, frequentemente acompanhados de "mais ou menos":

[...] no dia vinte e nove de Novembro do ano passado às duas horas da madrugada, mais ou menos. (Declaração de Joaquim, f. 25r, grifo nosso)

[...] aonde chegaram ás cinco horas da manhã mais ou menos. (Declaração de Joaquim, f. 26v, grifo nosso)

[...] na noite de vinte e oito de novembro do ano proximo passado, ás vinte e uma horas mais ou menos. (Declaração de Sebastião, f. 98r, grifo nosso)

${ }^{2} \mathrm{O}$ relato de Joaquim que trata da busca do dinheiro no esconderijo aparece em uma declaração complementar, datada de 12 de janeiro de 1938 (ALAMY FILHO, [197-?], p. 67-68). 
Benedito chegou da rua ás duas horas e meia da madrugada mais ou menos. (Declaração de Sebastião, f. 98v, grifo nosso)

Também se verifica a presença de pronome indefinido e do advérbio talvez:

[...] entrando para o mato, beirando uma cerca de [...] arame numa distancia de uns quinhentos metros ou talvez um kilometro. (Declaração de Joaquim, f. 26r, grifo nosso)

É interessante verificar que há uma interação entre a questão da descrição extremamente minuciosa e a da linguagem de incerteza: há a preocupação de fornecer grande quantidade de informação, mas essa informação não é necessariamente precisa, provavelmente em função de sua grande quantidade.

Um aspecto importante a ser salientado é que é especialmente significativa a presença simultânea das características acima citadas: é justamente essa simultaneidade que afasta fortemente a hipótese de ter havido algum tipo de coincidência com confissões (narrativas) não forjadas (isto é, confissões verdadeiras). Em face disso, tanto mais consistente será o resultado de uma análise dessa natureza no âmbito da linguística forense, quanto mais características diferentes e representativas forem encontradas em um dado texto submetido ao escrutínio de especialista. Justamente por isso, é importante buscar identificar outras características comuns a falsas confissões, tema da próxima seção.

O caso dos irmãos Naves é especialmente interessante por oferecer a possibilidade de identificar padrões de falsidade em confissões de diferentes indivíduos sobre um mesmo suposto crime. Por meio de métodos de comparação entre textos inspirados na crítica textual, observou-se a presença de características a que se nomeou aqui de eco e de padrões de condensação e expansão.

\subsubsection{Presença de eco}

O padrão a que se propõe aqui chamar de eco consiste na repetição de uma dada forma de codificar informação.

É bem possível que, para que não houvesse desconfiança sobre a falsidade das declarações, tenha havido alguma preocupação de dar a elas feições próprias, já que, sendo feitas pelos declarantes apartadamente (não estariam ambos presentes em cada declaração), seria improvável que apresentassem a mesma forma. Entretanto, essa atividade de individualização/personalização das declarações não terá sido totalmente eficaz, deixando para trás traços de repetição de codificação de informação, como nos exemplos abaixo:

[...] este logo em seguida procedeu a uma busca em Benedito, sacando da cintura deste um pano. (Declaração de Joaquim, f. 26r, grifo nosso)

[...] tendo então o declarante dado uma busca no seu cadaver, retirando da cintura deste um pano.

(Declaração de Sebastião, f. 98v, grifo nosso)

Observa-se, em ambos os trechos, a utilização de oração reduzida de gerúndio com a mesma ordenação de elementos ("da cintura deste um pano"), com especial atenção do uso de este como anafórico: trata-se do único caso em que a pronominalização com este ocorre no mesmo ponto das declarações. Esses fatos linguísticos sugerem que não se trata de declarações espontâneas feitas independentemente por pessoas distintas, pois tem-se as mesmas escolhas lexicais e sintáticas, o que significa que são produção linguística de uma única e mesma pessoa.

Dos casos de eco verificados, o mais significativo parece ser o seguinte: 
[...] fizeram de balisa duas arvores das proximidades. (Declaração de Joaquim, f. 26v, grifo nosso)

[...] fasendo de balisa duas arvores das proximidades. (Declaração de Sebastião, f. 99r, grifo nosso)

Trata-se de uma identidade surpreendente na forma de indicar a referência espacial para o lugar em que teria sido enterrada a lata com o dinheiro: novamente entram em questão escolhas lexicais e sintáticas iguais, tanto no que se refere ao uso de itens lexicais como balisa e proximidades, quanto no que diz respeito à ordenação dos constituintes.

\subsubsection{Padrões de condensação e expansão}

A análise comparativa das declarações dos irmãos Naves permitiu verificar também um padrão curioso de diferença textual.

Há, por um lado, uma condensação das informações da declaração de Joaquim (realizada antes) em relação à de Sebastião (realizada depois): não ocorre, na declaração de Sebastião, menção à posse de "uma corda de bacalhau de um metro e tanto" por Joaquim (f. 25v), ao movimento de liberação dos braços de Benedito por Sebastião (f. 25v), à confirmação da morte de Benedito por ambos os irmãos (f. 26r), ao lançamento do cadáver no Rio das Velhas (f. 26r), à ordem de parar o caminhão dada por Sebastião, à distância em que entraram para o mato (f. 26r) e à posse contínua da lata com o dinheiro por Sebastião (f. 26r e 26v). Chama ainda mais a atenção o fato de as informações presentes na declaração de Joaquim, mas ausentes na de Sebastião serem sobretudo supostas ações realizadas pelo próprio Sebastião. Como se trata de ações que não aconteceram efetivamente, vê-se que falsas confissões parecem ter especial função na incriminação de outros suspeitos: fala-se do outro, ausente do momento da declaração, justamente para envolvêlo no suposto crime. Há, portanto, que se desconfiar de declarações que deem grande ênfase à ação de outros indivíduos.

Há, por outro lado, uma expansão de informações na declaração de Sebastião, mas tratando de eventos posteriores aos últimos fatos narrados por Joaquim (procura por Benedito pela cidade e comunicação à Delegacia): Sebastião narra ter ocorrido posteriormente a prisão de ambos (f. 99r), seguida de liberação (f. 99r), a busca do dinheiro (f. 99r), a entrega para sua mãe (f. 99r) etc.

A impressão que se tem em relação a esse processo simultâneo de condensação e expansão é de que a primeira declaração não foi suficiente para criar uma narrativa verossímil (não se encontraram depois o corpo de Benedito nem o dinheiro), então a segunda declaração tinha como função "remendar" a primeira narrativa para dar conta dos fatos não explicados, como foi o caso de aparecer apenas na declaração de Sebastião a alegação de que o dinheiro teria sido entregue posteriormente à sua mãe (caso de expansão). No que se refere à condensação, ela também parece ser um "remendo", pois, como não foi possível encontrar o corpo de Benedito, todos os fatos relacionados à sua execução foram mitigados na declaração de Sebastião: sua retomada nessa declaração aumentaria a pressão em relação à localização do corpo, algo que, obviamente, não poderia ser conseguido, já que Benedito não havia sido morto.

\section{CONCLUSÃO}

Neste artigo, foi realizada uma análise linguística e discursiva das falsas confissões atribuídas a Joaquim e Sebastião no famoso caso dos irmãos Naves, em que os acusados foram injustamente condenados pelo cometimento de um suposto latrocínio. Embora limitado pela natureza dos dados - já que as declarações disponíveis foram ditadas pela autoridade policial e não transcritas a partir da fala dos acusados - , este estudo fornece subsídios para discussões sobre como melhor caracterizar falsas confissões em contextos investigativos e judiciais, com a proposição de dois novos aspectos a serem considerados nesse tipo de análise.

Foram discutidos aspectos linguísticos e discursivos que, de acordo com a literatura sobre linguística forense consultada, são característicos desse tipo de narrativa. Em seguida, as falsas confissões atribuídas a Joaquim e Sebastião Naves foram analisadas à luz desses aspectos a fim de se identificar em que medida elas próprias carregam características presentes em outras falsas confissões, e observou-se a presença de três características citadas na literatura sobre o tema. 
Complementarmente, por meio da adoção de um método inspirado na crítica textual, foi possível identificar ainda duas outras características passíveis de verificação apenas em casos de declarações de diferentes acusados sobre um mesmo suposto crime. Dessa forma, este artigo não apenas verifica a presença de características já observadas em trabalhos anteriores, mas também sugere outros elementos que podem ser analisados em casos de dupla ou múltipla confissão.

Falsas confissões são um problema que deve ser combatido e diversos estudos sugerem maneiras para isso (BROHOLM, 2011; VALDERRAMA, 2011). Em um escopo mais amplo, um objetivo deste trabalho é fornecer subsídios para a discussão acerca de características linguísticas presentes em falsas confissões, com a finalidade de contribuir para identificar e remediar esse fenômeno. Como demonstrado aqui, o diálogo entre diferentes campos do conhecimento que se ocupam da linguagem humana, como a linguística forense e a crítica textual, são certamente um caminho enriquecedor para a abordagem do tema, pois, sendo a linguagem uma realidade multifacetada, é natural que sua compreensão envolva a articulação de diferentes saberes. Outra contribuição deste estudo jaz no fato de ser uma das primeiras investigações sobre falsas confissões envolvendo um caso ocorrido no Brasil.

No futuro, pretende-se ampliar as análises aqui realizadas para que sejam consideradas também outras declarações confessionais dos irmãos Naves e de seus familiares que constam dos autos do processo. Espera-se, a partir dessas e de outras observações sobre o tema, que uma tipologia de falsas confissões seja construída e que possa ser utilizada, em conjunto com outros métodos, para auxiliar na identificação de falsas confissões.

\section{REFERÊNCIAS}

ALAMY FILHO, J. O caso dos irmãos Naves: o erro judiciário de Araguari. São Paulo: Círculo do Livro, [197-?].

ALMEIDA, J. C. M. de. O princípio da verdade real. Revista da Faculdade de Direito, São Paulo, v. 52, p. 116-138, 1957.

BARTHES, R. O efeito de real. In: GENETTE, G.; BARTHES, R.; KRISTEVA, J; TODOROV, T.; BREMOND, C. (org.). Literatura e semiologia. Pesquisas semiológicas. Petrópolis: Vozes, 1972. p. 35-44.

BIZ, A. M. O caso dos irmãos Naves: o erro judicial de Araguari. 2012. 41 f. Trabalho de conclusão de curso (Graduação em Direito) - Instituto Municipal de Ensino Superior de Assis, Assis, 2012.

BROHOLM, T. M. Reducing false confessions through video recording. In: THOMPSON, S. G.; HOPGOOD, J. L.; VALDERRAMA, H. K. (org.). American justice in the age of innocence: understanding the causes of wrongful convictions and how to prevent them. Bloomington: iUniverse, 2011.p. 79-117.

CAMBRAIA, C. N. Introdução à crítica textual. São Paulo: Martins Fontes, 2005.

DOTTI, R. A. Casos criminais célebres. 3. ed. São Paulo: Editora Revista dos Tribunais, 2003.

DRIZIN, S. A.; LEO, R. A. The problem of false confessions in the post-DNA world. North Carolina Law Review, Chapel Hill, v. 82, n. 3, p. 891-1008, 2004.

DUTRA, L. C. A abordagem processual escrita da confissão: erros de interpretação, erros na busca pela verdade real. Revista Thesis Juris, São Paulo, v. 4, n. 1, p. 187-203, jan./jun. 2015. 
FIGUEIREDO, S. A. F. O caso dos irmãos Naves: uma leitura sob ótica da criminologia crítica e teoria da vulnerabilidade de Eugenio Raúl Zaffaroni. In: SEMINÁRIO AMÉRICA LATINA: CULTURA, HISTÓRIA E POLÍTICA, 2015, Uberlândia. Anais... Uberlândia: Pueblo Editora / Nepri-UFU, 2015.

GARRETT, B. L. The substance of false confessions. Stanford Law Review, Stanford, v. 62, p. 1051-1118, abr. 2010.

GARRETT, B. L. Contaminated confessions revisited. Virginia Law Review, Charlottesville, v. 101, n. 2, p. 395-454, abr. 2015.

GREBLER, G. A jihadi heart and mind? Strategic repackaging of a possibly false confession in an anti-terrorism trial in California. In: COULTHARD, M.; JOHNSON, A. (org.). The Routledge handbook of forensic linguistics. New York: Routledge, 2010. p. 315-332.

GUDJONSSON, G. H.; SIGURDSSON, J. F. How frequently do false confessions occur? An empirical study among prison inmates. Psychology, Crime and Law, London, v. 1, n. 1, p. 21-26, 1994.

KASSIN, S. M.; WRIGHTSMAN, L. S. Confession evidence. In: KASSIN, S. M.; WRIGHTSMAN, L. S. (org.). The psychology of evidence and trial procedure. Beverly Hills: Sage Publications, 1985. p. 67-94.

MARQUILHAS, R.; CARDOSO, A. O estilo do crime: a análise de texto em estilística forense. In: COSTA, A.; FLORES, C.; ALEXANDRE, N. (ed.). Textos selecionados, XXVII Encontro Nacional da Associação Portuguesa de Linguística. Lisboa: APL, 2012. p. 416-436.

MUSEU DO JUDICIÁRIO MINEIRO. O caso dos irmãos Naves disponível para consulta. 2017. Disponível em: http://museudojudiciariomineiro.com.br/o-caso-do-irmaos-naves-disponivel-para-consulta/. Acesso em: 06 jul. 2019.

NEIVA, A. E. D. Confissões: a perspectiva de investigadores mais e menos experientes. 2006. 92 f. Dissertação (Mestrado em Psicologia Aplicada) - Instituto Superior de Psicologia Aplicada, Lisboa, 2008.

OLIVEIRA, E. R. de. O erro judiciário de Araguari na literatura. Revista Crioula, São Paulo, n. 11, maio 2012.

OLIVEIRA, E. R. de. O caso dos irmãos Naves: processamentos artísticos a partir de um erro jurídico. 2013 . 165 f. Dissertação (Mestrado em Artes) - Universidade Federal de Uberlândia, Uberlândia, 2013.

RODRIGUES, E. “O caso dos irmãos Naves”: um registro de memória por João Alamy Filho. Emblemas: Revista do Departamento de História e Ciências Sociais (UFG/CAC), Catalão, v. 8, n. 2, p. 73-88, jul./dez. 2011.

SILVA, C. G. da. O caso dos irmãos Naves: “Tudo o que disse foi de medo e pancada.... Revista Liberdades, São Paulo, n. 4, p. 78-85, maio/ago. 2010.

SILVA, W. B. da. Princípio da presunção de inocência: caso dos irmãos Naves. Revista da Católica - Faculdade Católica de Uberlândia, Uberlândia, v. 3, n. 5, 2011. 
SOUSA, M. P. de. "O caso dos irmãos Naves": o poder coercitivo da farda. 1996. 76 f. Monografia (Graduação em História) Universidade Federal de Uberlândia, Uberlândia, 1996.

VALDERRAMA, H. K. Of crimes, confessions, and convictions: reducing wrongful convictions attributable to false confessions. In: THOMPSON, S. G.; HOPGOOD, Jennifer L.; VALDERRAMA, H. K. (org.). American justice in the age of innocence: understanding the causes of wrongful convictions and how to prevent them. Bloomington: iUniverse, 2011. p. 119-192.

\section{(ㄷ) (i) $(9)$}

Recebido em 12/07/2019. Aceito em 01/10/2019. 


\section{ANEXO A - TEXTOS TRANSCRITOS}

\section{TRANSCRIÇÕES DAS DECLARAÇÕES DOS IRMÃOS NAVES}

As transcrições que se seguem foram feitas a partir do fac-símile do processo dos irmãos Naves disponibilizado pelo Museu do Judiciário Mineiro. Utilizaram-se: versalete para texto impresso de formulário; barra reta para mudança de folha; colchetes duplos para repetição e/ou correção do escrivão; sic para confirmação de presença de forma aparentemente estranha; e sublinhado com itálico para assinaturas.

\section{"DECLARAÇÕES PRESTADAS POR: Joaquim Naves Rosa}

AOS doze (12) DIAS dO MEZ DE janeiro DE MIL NOVECENTOS E TRINTA E oito, NESTa cidade de Araguari, ESTADO DE MiNAS Geraes, em a (sic) Delegacia de Polícia, Onde Se aChaVa OSR. $1^{\circ}$ Te. Francisco Vieira dos Santos, Delegado de POlícia, COMmigO ESCRivão privativo DO SEU CARGO AFINAL NOMEADO E ASSIGNADO, AHI COMPARECEU Joaquim Naves Rosa, COM 25 ANNOS DE EDADE, DE CÔR branca, ESTADO CIVIL casado, PROFISSÃO chaufeur, FILHO DE José Antonio de Oliveira e Ana Rosa Naves, DE NACIONALIDADE brasileira, NATURAL DE Ponte Nova, município de Monte Carmélo, RESIDENTE nesta cidade, na Vila Marques, SABENDO LÊR E ESCREVER, DECLAROU O SEGUINTE:

Que, no dia vinte e nove de Novembro do ano passado ás duas horas da madrugada, mais ou menos estava [[o depoente digo]] o declarante em compania de seu irmão Sebastião José Naves em sua casa, nas proximidades da venda de Manoel Marques, esperando a chegada de Benedito Pereira Caetano afim de convidá-lo para um passeio a Uberlandia, isto de | [[isto de]] combinação com o seu irmão Sebastião José Naves; que, poucos momentos depois chegava Benedito Pereira Caetano, na casa do declarante, sendo então convidado pelo o (sic) declarante e o seu irmão Sebastião, para o dito passeio a Uberlandia; que, Benedito Pereira aceitou o covite (sic) para o passeio referido, entrando no mesmo momento todos os treis para dentro do caminhão pondo-o em marcha, tomando a direção da ponte "Pau Furado", isto ás treis horas da madrugada; que, depois [[depois]] de atravessarem a referida ponte, isto pelas quatro horas da madrugada, mais ou menos, apearam do dito caminhão, o declarante, seu irmão Sebastião e Benedito, com o fim de tomarem agua; que, desceram o paredão até a margem do rio, estando o seu irmão na frente, Benedito no centro e o declarante atrás, o qual levava oculta uma corda de bacalhau de um metro e tanto; que, chegados na beira do rio, apos beberem agua, Sebastião agarrou Benedito pelas costas e o declarante fez um nó na dita corda introduzindo-a pela cabeça de Benedito até o pescoço apertando-a logo em seguida, e Sebastião em um movimento brusco largou os braços de Benedito auxiliando o declarante a apertar a corda; que, Benedito nesse momento desfaleceu, caindo de joelhos | [[caindo de joelhos]] até ficar sem vida o que foi verificado pelo o (sic) declarante e seu irmão Sebastião; que, este logo em seguida procedeu a uma busca em Benedito, sacando da cintura deste um pano que o mesmo trazia amarrado á cintura, por dentro da cueca e onde o declarante e o seu irmão sabia (sic) que existia a importancia mais ou menos de noventa contos de reis em dinheiro, cuja importancia o seu irmão Sebastião, depositou em uma latinha de soda adrede preparada pelo o (sic) declarante para esse mesmo fim que transportou-a de sua casa; que, em seguida o seu irmão Sebastião pegou o cadaver de Benedito pela cabeça e o declarante pelo os (sic) pés, atirando-o na cachoeira do Rio das Velhas, do lado de baixo da ponte, tendo deixado na beira do dito rio a corda com que se utilisaram para a execução do crime e o pano onde continha o dinheiro que a vitima conduzia; que, em seguida tomaram o caminhão de volta para esta cidade; que, em uma certa altura, nas proximidades da fazenda de Olympio de Tal, o declarante que guiava o caminhão, fez uma parada por ordem do seu irmão Sebastião, que conduzia o dinheiro, deixando em seguida o caminhão na estrada entrando para o mato, beirando uma cerca de [[arome, numa digo]] arame numa distancia de uns quinhentos metros ou talvez um kilometro | [[um kilometro]], pararam ambos em uma moita de capim gordura onde Sebastião começou a cavar um buraco com as unhas, sempre de posse da lata onde se continha o dinheiro e, auxiliado pelo o ( sic) declarante que ainda ajudou a acabar de furar o dito buraco, onde enterraram a lata que continha o dinheiro. Diz o declarante que fizeram de balisa duas arvores das proximidades afim de que em ocasião oportuna fossem retirar o fruto do saque; que, após terminarem esse serviço o declarante e o seu irmão Sebastião rumaram para esta cidade com destino [[as suas respectivas casas; que, digo]] as suas respectivas casas aonde chegaram ás cinco horas da manhã mais ou menos; que, ás sete horas chegou novamente em sua casa o seu irmão Sebastião que com o declarante concertaram o plano de procurarem Benedito pela cidade, o que fizeram chegar ao conhecimento de diversas pessoas estes seus cuidados pelo o (sic) desaparecimento da vitima, trazendo tambem o fato ao conhecimento [[desta delegacia; que, digo]] desta delegacia. Diz o declarante que assim procederam com

Cunha \& Cambraia A linguagem de uma fraude: análise das falsas confissones atribuídas aos irmãos Naves 
o fim exclusivo de pretestarem ( $\mathrm{sic}$ ) inocencia. E como nada mais disse e nem lhe foi perguntado, mandou a autoridade encerra (sic) este auto, que, depois de | lidas e achadas conforme, assina com o declarante, testemunhas e comigo, Aulete Ferreira, escrivão, o escrevi.

\section{Tte. Francisco Vieira dos Santos}

Joaquim Naves Rosa

Sebastião Vieira de Sousa

Losé Moreira

Aulete Ferreira" (fls. 25r-27r)

\section{“DECLARAÇÕES PRESTADAS POR: Sebastião José Naves}

AOS treis (3) DIAS DO MEZ DE fevereiro DE MIL NOVECENTOS E TRINTA E oito, NESTa cidade de Araguary, EstaDO DE MINAS Geraes, em a (sic) Delegacia de Polícia, onde Se achava o Sr. 1. Tte. Francisco Vieira dos Santos, delegado de POlícia, COMigo ESCRivão privativo DO SEU CARGO AFINAL NOMEADO E ASSIGNADO, AHI COMPARECEU Sebastião José Naves, COM 33 ANNOS DE EDADE, DE CÔR branca, ESTADO CIVIL casado, PROFISSÃo lavrador, FILHO DE José Antonio de Oliveira e Ana Rosa Naves, DE NACIONALIDADE brasileira, NATURAL DE o (sic) município de Monte Carmelo, neste Estado, RESIDENTE nesta cidade, Vila Marques, SABENDO LÊR E ESCREVER E DECLAROU O SEGUINTE:

Que, na noite de vinte e oito de novembro do ano proximo passado, ás vinte e uma horas mais ou menos, o declarante [[concertou com o seu irmão Joaquim, para convidarem digo,]] concertou com o seu irmão Joaquim, o plano de convidarem Benedito Pereira Caetano, que com eles residia, para irem dar um passeio a Uberlandia e, quando chegassem na Ponte do Pau Furado, sobre o Rio das Velhas, ele declarante e Joaquim, matariam Benedito e roubariam o dinheiro que este | conduzia; que, após concertarem o referido plano, o declarante e seu irmão Joaquim dirigiram-se para as suas respectivas residencias, afim de aguarda $[[\mathrm{m}]]$ rem a chegada de Benedito que se achava na rua; que, Benedito chegou da rua ás duas horas e meia da madrugada mais ou menos, sendo então the feito o dito convite pelo o (sic) declarante e Joaquim; que, Benedito aceitou o convite que lhe era feito, partindo todos os treis no caminhão de Joaquim, ás treis horas da mesma madrugada; o declarante, Joaquim e Benedito; que, chegados na referida Ponte do Pau Furado, pararam o caminhão e convidaram Benedito para beberem agua; que, este aceitando o convite dirigiram-se para as margens do rio; que, após beberem agua, o declarante segurou Benedito por detrás e mandou que Joaquim puzesse a corda no pescoço de Benedito, cuja corda Joaquim já havia feito um nó; que, Joaquim no mesmo momento enlaçou a dita corda no pescoço de Benedito enforcando-o; que, Benedito morreu no mesmo instante, tendo então o declarante dado uma busca no seu cadaver, retirando da cintura deste um pano, e no qual o declarante verificou mais tarde conter a importancia de noventa contos de reis, embora o seu irmão Joaquim dizer que o mesmo continha noventa e dois contos de reis, podendo o declarante estar enganado neste ponto; [[que, em seguida, digo,]] que, depois de retirar o dinheiro da cintura de Benedito o declarante colocou o dito dinheiro em uma lata de soda, tomando em seguida o caminhão com o seu irmão Joaquim e dirigiram-se rumo a esta cidade; que, chegados nos terrenos de propriedade de Olympio Bernardes, pararam | [[pararam]] o caminhão, margearam uma cerca de arame, entraram depois para o mato e em uma moita de capim, escavaram com as mãos um buraco, enterrando ali a dita lata de soda na qual continha o dinheiro, fasendo de balisa duas arvores das proximidades; que, após enterrarem a lata de soda, tomaram novamente o caminhão seguindo com destino a esta cidade, aonde chegaram ás cinco horas da manhã, dirigindo-se cada um para a sua residencia; que, ás sete horas e vinte minutos d’aquela mesma manhã, o declarante foi até a casa de seu irmão Joaquim e ahi o convidou para ambos procurarem Benedito pela cidade, afim de que sobre eles não recahisse (sic) suspeitas; que, poucos dias depois o declarante e Joaquim foram presos como suspeitos no desaparecimento de Benedito; que, a polícia, nada apurando no momento, poz Joaquim e o declarante em liberdade; que, estando em liberdade, o declarante mandou o seu irmão Joaquim no local onde haviam enterrado o dinheiro e o trouxesse para esta cidade, sendo isto no dia dez de dezembro do ano já citado; que, Joaquim cumprindo o mandado do declarante foi ao referido local, trazendo o dinheiro e o entregando a sua mãe Ana Rosa Naves, em presença do declarante, que já esperava a chegada de Joaquim, sendo ahi então contado o referido dinheiro pelo o (sic) declarante e Joaquim, sendo a importancia de noventa contos de reis mais ou menos, ficando esta em poder de sua mãe como já disse acima; que retifica a parte acima em que consta que o declarante assistiu seu irmão Joaquim entregar o dinheiro a sua mãe, pois o declarante não assistiu dita entrega; que, tendo mandado Joaquim buscar o dinheiro no esconderijo que arranjaram na madrugada do crime, foi Joaquim fazer essa missão, mais ou menos no dia dez de dezembro do ano | [[ano]] proximo findo, como consta acima; que Joaquim voltou, mais ou menos ás treze horas, estando o declarante a espera d’aquele e na casa d’ele, Joaquim; que, nesse momento estava ausente a 
senhora de Joaquim e cunhada do declarante; que, então na cosinha, contou com o seu irmão a quantia que ele trouxera do esconderijo; que, segundo acha o declarante a quantia era de noventa contos de reis, dizendo seu irmão Joaquim ser de noventa e dois contos, havendo pois um pequeno engano de um ou de outro; que, desde esse dia não viu mais aquele dinheiro que ficou com Joaquim; que no dia imediato Joaquim e sua família foram para a Ponte Nova, de caminhão, tendo o declarante seguido no mesmo caminhão até certo ponto do caminho, de onde se separou de Joaquim e sua família para seguir, em outro caminhão para a fazenda de seu cunhado "Inhozinho", João Antonio de Oliveira; que, desde o dia acima declarado em que contou na casa de Joaquim e com este o dinheiro não mais conversou com êle sobre o destino dado ao dinheiro. E como nada mais disse nem lhe foi perguntado, mandou a autoridade encerrar este, que, depois de lido e achado conforme, assina com o declarante e as testemunhas presentes: Dickson Machado, João Ribeiro e José Falcomer, residentes nesta cidade, e comigo Aulete Ferreira, escrivão, que o escrevi.

\section{Tte. Francisco Vieira dos Santos}

Sebastião José Naves

Dickson Machado

Loão Ribeiro

Losé Falcomer

Aulete Ferreira" (fls. 98r-99v) 